\title{
PROBLEMAS JUDICIALES EN LA LEGISLACIÓN NOVELAR JUSTINIANEA: LA LENTITUD Y COSTO DE LOS LITIGIOS
}

\author{
FERMÍN CAMACHO
}

En el prefacio de la Novela 125, del año 544, se indica:

Quoniam quidam iudicantium post multa litis certamina et plurima a litigantibus facta dispendia in negotiis apud eos motis suggestionibus utumtur ad nostram traquillitatem, praesente generali lege hoc perspeximus emendare, ne dilationes negotiis ex hoc fiant, et aliud rursus principium examinationes accipiant ${ }^{1}$.

El problema que se pretende evitar es aquel de la excesiva duración de los juicios - ne in causis dilationes fiant- $\mathrm{y}$, consecuentemente, de los perjuicios $\mathrm{y}$ gastos que por esta causa deben afrontar las partes. El motivo, según Justiniano, es la práctica frecuente en los juicios de reenviar todas las causas a la supervisión del Emperador, después de un ya largo y costoso iter procesal - multa litis certamina - de una relatio y, a su tenor, con la paralización de la sentencia hasta la llegada de la respuesta imperial.

La cuestión de la lentitud y costo de la justicia se encuadra en la conocida degradación judicial operada en época justinianea. Era propio de los abogados retardar las decisiones de los procesos, ya de por sí no suficientemente veloces, a través de continuas propuestas de reenvío de la causa, o paralizando la audiencia para mejor documentarse sobre los hechos de la controversia ${ }^{2}$. Como también es conocido el estado de los tribunales y la corrupción de los jueces que, con habitual frecuencia, no se encontraban en grado de asegurar una justicia imparcial, frente a los perjuicios que el retardo de sus decisiones creaba en los litigantes con menos medios económicos ${ }^{3}$.

1 A fin de un análisis exhaustivo del prefacio de esta Novela, resulta imprescindible la consulta de PESCANI, «Recensione a Bassanelli Sommariva», en BIDR n ${ }^{\circ}$ 85, 1982, p. 336 y ss.

2 U. VINCENTI, «Ante sententia appellari potest», contributo allo studio dell appellabilitá della sentanza interlocutoria nell processo romano, Padova 1986, pp. 33-37.

3 Según opinión generalizada en la doctrina, la causa principal del retardo de los procesos en esta época era la actitud obstrucionista de la mayoría de los abogados, estos aprovechaban al máximo las incertezas legales, y los conflictos jurisdiccionales de los tribunales, para dilatar las acciones legales, ya sea para hacer aumentar sus honorarios, sea para favorecer a los clientes con una economía más holgada frente a las partes menos pudientes. Con frecuencia los abogados, observando la incompetencia de los jueces, promovían un argumento legal complicado que retardaba la causa, enviando relationes al Emperador para que se examinará el caso, y frente a su posible abuso, Justiniano intenta abolir este dilatorio hábito con la Nov. 125. 
Otras causas que justifican esta demora en la conclusión de los litigios eran debidas, como indica la Nov. 49pr., a un mero problema de lentitud de comunicaciones. Justiniano ordena que las apelaciones se presenten en un plazo máximo de dos años, la Novela nos precisa las quejas de muchos apelantes:

"Quia igitur multi a dierum nos ex Caria et Rhodo et Cypro, difficultatem patientes, et dicentes, cogi se frequenter hiemis tempore venire ad Scythiam et Mysiam ubi degis, et ibi appellationes forte neque pro magnis pecuniis, exercere et periclitari, etiam maria transeuntes longa et venientes ad provincias a barbaris inquietatas, propterea perpeximus hanc legem scribere ad tuam gloriam ut ex Scythia quidem et Mysia causas tamquam ex vicinis existentes, tua celsitudo secundum se audiat, alias vero, hoc est ex Caria et praedictis insulis, et Cypro, si ab initio ipsae apud gloriossimos nostros praefectos exercebantur...»

Con frecuencia encontramos, durante época justinianea, esta inquietud del Emperador por la dilación de los juicios ${ }^{4}$ C.I.3,1,13:

\begin{abstract}
Properandum nobis visum est, ne lites fiant paene immoratae criminales quidem causas iam nostra lex biennio conclusit, et pecuniariae causae frecuentiores sunt, et saepe ipsae materiam criminibus creare noscuntur, praesentem legem super his orbi terrarum, nullis locorum vel temporum angustiis coarctandam, ponere.
\end{abstract}

4 Algunos romanistas entienden que una de las razones que alientan la tarea codificadora de JUSTINIANO, es remediar la excesiva lentitud de los litigios, tomando en consideración que la constitución «Haec quae necessario» indica que el objetivo perseguido por el emperador, con el Codex del 528, era "prolixitas litium amputare», más específicamente, facilitar la «recitatio constitutionum», es decir, la lectura de los textos legales por los jueces, con finalidad de acelerar la decisión de los procesos.

F. GALLO, La codificazione giustinianea, en INDEX XIV, 1986, p. 2 y ss.; BONINI, Introduzione allo studio dell'etá guistinianea, Bologna 1989, p. 19 y ss.; BIANCHINI, Osservazioni minime sulle costituzioni introduttive alla compilazione giustinianea, en Studi In Memoria di DONAIUTI, vol. I, Milano 1973, p. 122 y ss.; ARCHI, Giustiniano legislatore, Bologna 1970, p. 125 y ss.; VICENTI, "Ante sententiam appellari potest», contributo allo studio dell' appellabilita della sentenza interlocutoria nel processo romano, Padova 1986, p. 104 y ss.

También podemos destacar esta orientación imperial, sobre la dificultad de acelerar la conclusión de los litigios, en otras constituciones:

Const. «Summa rei publicae», cap. I: «Sed cum necessarium multitudinem constitutionum (...) ad brevitatem reducendo caliginem earum rectis iudicum definitionibus insidiantem penitus extirpare»

Const. «Tanta» cap. XVII: «Homines etenim, qui antea lites agebant, licet multae leges fuerant positae, tamen ex paucis lites preferebant vel propter inopiam librorum quos conparare eis imposibile erat, vel propter ipsam inscientiam, et voluntate iudicum magis quam legitima auctoritate lites dirimebantur.» 
Múltiples son las soluciones que se pretenden arbitrar para hacer el camino de la justicia más rápido, por ejemplo, establecer que delante de los tribunales de primer grado, con respecto a las acciones civiles, se debía realizar juicios en el plazo de tres años, mientras que en los penales el plazo se reduce a dos años; así como que «in quancumque lite» no se pueda acudir al recurso de la apelación más de dos veces ${ }^{5}$ (C.I.7,70,1 o en la Nov. 82,56), o, como nos señala C.I.7,63,57, cuando son causas presentadas en Asia, Ponto o Tracia, se deben resolver en tres meses como plazo máximo.

Otro motivo de retraso eran las maniobras dilatorias, a través de ellas las partes intentaban cansar al contrario, fundamentalmente no presentándose a la audiencia, y retardando intencionadamente la decisión; circunstancia que, como primera consecuencia, hacia elevar de forma notable el costo del proceso, convirtiéndolo, con frecuencia, en inviable para partes menos pudientes; el propio Emperador nos indica este inconveniente en C.I.3,1,13,2

Et si quidem pars actoris cessaverit, quatenus multiplici dilatione reus fatigetur...

Los jueces de las cortes intermedias no tenían ningún motivo para desviar el curso normal del proceso, si ambas partes podían corromperlos en la misma

5 Sobre esta prohibición consultar ARU, Il processo civile romano, Roma 1934, p. 72 y ss.; así como ORESTANO, L'appello civile in diritto romano, Torino 1966, p. 352 y ss.

6 C.I.7,70,1 «Si quis in quacumque lite iterum provocaverit, non licebit ei tertio in eadem lite super iisdem capitulis provocatione uti, vel sententias excellentissimorum praefectorum praetorio retractare; licentia danda litigatoribus, arbitro dato, ipsi 8 audientiam, qui eum dedit, ante litis contestationem invocare, et huiusmodi petitione minime provocationis vim obtinente»

Nov.82.5 del año 539 «Audient igitur omnes quidem litem usque ad trecentos solidos exsistentem sub schemate annotationis. Sic enim velocius lites iudicabuntur, et circulis cognitinalibus hac temporis contritione omnes litigantes liberabuntur. Palam vero est, quia, etsi per annotationem audient causas, verumtamen dabunt terminum per scripturam, qui eorum manifestet sententiam; appellationibus in his nulli penitus perimendis, nisi forte tertio appellare voluerit, aut per contumaciam defuerit; talibus enim etiam appellationum perimitur ratio».

7 C.I.7,63,5 «...Sin autem ex aliis nostris imperii patibus sive Asianae sive Ponticae sive Thraciae dioeceseos, lis provocatione suspensa in hanc regiam urbem perveniat, pro semestri spatio trium tantummodo mensium spatium eis indulgerit; aliis trium mensium spatiis, id est nonaginta tribus diebus, simili modo sequentibus sive semestre tempus sive tres priores menses, secundum locorum definitionem, quam designavimus...»

En este supuesto, si la audiencia no se celebraba en el día fijado, el apelante podía reclamar que la causa fuese concluida en el término de tres meses, y, si en el segundo día fijado el juez, o una de las partes, se presentára un impedimento razonable para su celebración, se podía pedir una segunda convocatoria también en el término de tres meses. Así mismo, podía ocurrir que cuando un apelante iniciara la causa, podía pasar todavía un largo período de tiempo antes de la audiencia, con objeto de que el apelante pudiera cansar a su adversario con técnicas dilatorias, evitando el transcurso normal del litigio. 
medida, o si ninguna tenía la suficiente capacidad para presionarlo. Si por el contrario, una de las partes era un sujeto acaudalado frente a la otra humilde, difícilmente este último podía obtener una justicia objetiva, ya que cuando la parte más pudiente era convenida, con frecuencia, podía reclamar, a través de la praescriptio fori, la jurisdicción de un tribunal lejano y costoso, tanto que el otro adversario no podía soportar los gastos; así como cuando la parte rica era el actor del litigio podía recurrir, por medio de un rescripto especial, a un tribunal superior, haciendo que la otra parte, a la vista de los posibles gastos derivados del proceso, cediera a sus pretensiones antes de la conclusión de la causa ${ }^{8}$.

La cuestión de los gastos procesales cobra en derecho justinianeo una singular importancia, al estar inevitablemente conexa a la posibilidad de una justicia real y objetiva en los procesos también para las partes más humildes.

Como es lógico, el problema de las costas procesales se debe observar teniendo bien presente la evolución operada dentro del ámbito de la estructura del proceso. Sabemos que durante la época en la que se desarrollaron las legis actiones, así como durante el proceso formulario, en donde los magistrados ejercían su jurisdicción, como medio de encauzar el litigio, de forma gratuita, -incompatible con cualquier tipo de retribución económica-, no se plantean cuestiones sobre los posibles gastos procesales, siendo además estos mínimos al comprender, únicamente, los derivados de los medios de prueba, o aquellos procedentes de las retribuciones, reducidas en estas épocas, de los abogados y procuradores.

Esta facilidad de acceso a los tribunales, frente a la casi gratuidad de la justicia, tuvo como efecto negativo que los litigios se multiplicaban innecesariamente, colapsando la administración judicial y dilatando las causas de forma maliciosa. A este tenor, durante época clásica, se emitieron las poenae temere litigantium, destinadas a sancionar y desalentar al litigante temerario; quien litiga conociendo con seguridad su falta de razón o apoyo jurídico, con la sola intención de alterar el normal curso de los procesos; dichas penas, sin alterar la gratuidad procesal, imponían una condena al duplum, compensándose a la parte vencedora en el litigio de los gastos generados en el desarrollo del proceso.

Las costas procesales van a sufrir un importante incremento con el desarrollo de la cognitio extra ordinem, debido a los gastos originados tanto por la propia

8 Quizás solo frente al defensor civitatis los litigantes menos pudientes podían esperar obtener unas causas más económicas y ágiles, básicamente si las partes encontraban un acuerdo, o cuando se sustanciaba la causa frente al gobernador y este juzgaba sine scriptis, de forma gratuita. En ambos supuestos, el procedimiento se desarrollaba sin grandes requisitos formales, los abogados de las partes se limitaban a dar sugerencia al juez, quien, a su vez, se esforzaba en indagar sobre los hechos a través de testimonios e interrogando a las partes. Para profundizar en estos supuestos ver JONES, I1 tardo imperio romano, Milano 1973, p. 737 y ss. 
administración de justicia (las sportulae debidas a la expedición de certificados, redacción de actas o gastos de citación ${ }^{9}$ ), como por el notable incremento de los honorarios de abogados y procuradores ${ }^{10}$. De aquí que, tomando en consideración el grave perjuicio que se puede provocar, por el alto incremento de los gastos procesales, a causa del inicio temerario de un litigio, se inicia a implantar el criterio de la imputación de costas al litigante vencido en el juicio, a causa de reconocerle una «temeritas» procesal; un principio que también afecta a quien apela de forma infundada o maliciosa.

A título de ejemplo se puede recordar D.5,1,79pr., referente a los gastos procesales de las partes en los procesos sustanciados ante al gobernador provincial, que indica que el improbus litigator, al litigar de forma manifiestamente temeraria, contrae la obligación de soportar el reembolso a la parte contraria de las costas procesales ${ }^{11} \mathrm{y}$ de los gastos generados por el viaje ${ }^{12}$ a la sede del tribunal:

Eum, quem temere adversarium suum in iudicium vocasse constitit, viatica litisque sumptus adversario suo reddere oportebit.

Una fuente clásica sobre el argumento de las costas procesales es una constitución de Zenón C.I.7,51,5 ${ }^{13}$

Constitutio sancit, ut omnis iudex in sententia sua iubeat victum praestare omnes expensas in iudicio erogatas; concessa ipsi iudici potestate et excedendi summam expensarum ad decimam usque partem eorum, quae impensa sunt, si eum victi impudentia ad hoc permoverit, ita ut id, quod expensas excedit, ad publicas rationes pertineat, nisi

9 Las «sportulae», como retribución por la intervención de la administración de justicia, también fueron objeto de una precisa regulación de su cuantía y forma, en C.Th. 1,16,7, hubo un intento de supresión por el emperador Constantino, más tarde, a través de C.Th. 1,52, en una constitución de Teodosio II y de Valentiniano III, se intentaron simplemente reducir su cantidad en su consideración de aranceles. Para finalizar en Justiniano C.I. 3,2 «de sportulis et sumptibus in diversis iudiciis faciendis et de exsecutoribus litium».

10 Este incremento en las retribuciones de abogados y procuradores fue, en frecuentes ocasiones, legalmente controlado y restringido, frente a los habituales abusos que la práctica judicial dejaba de manifiesto. El Edicto de Diocleciano «de pretiis rerum venalium» 7,72 , fue un claro ejemplo de este control «Advocato sive iurisperito mercedis in postulatione ducentos quinquagnita. In cognitione mille».

11 En realidad, el término «costas» no es genuino de las fuentes romanas, el concepto más idóneo es el de «expensas» $\mathrm{y}$, en ocasiones, «impensas», «sumtus» $y$ «dispendia». Y aunque existen autores, como es el caso de MAYNZ, que hablan del carácter indiscriminado en las fuentes en la utilización de estos términos, nos parece más acertada y precisa la tesis de CHIOVENDA (opus cit. p. 35 y 36 -en particular la n. 2-) que considera que el término «expensas» es el utilizado en las constituciones imperiales, mientras que «impensae» es más usado por los jurisconsultos clásicos.

12 Que solían estar calificados con el término «misiones».

13 Esta constitución fue desconocida hasta que Cuiacio la incorporó CUIACIO, Observat., XII, cap. I-B. p. 9,3 y 69. 
forte iudex, morae detrimentum parti victrici sarcire volens, partem aliquam eorum addicat; condemnando non solum actore et reo, si iudex utrique competens sit, verum etiam si actori sit incompetens, si is vincatur ex reconventione, quum non possit illum iudicem recusare, sive praesides iudices fuerint, sive delegati a principe arbitri; nam et hi exsecutores et compulsores habent. Quodsi iudex hoc non fecerit, ipse hoc damnum victrici parti sarcire cogitur.

El juez debe condenar al vencido en la causa, al pago de todas las costas invertidas en el juicio ${ }^{14}$, pudiéndose además aumentar tal cuantía hasta en un décimo más a favor del erario, salvo cuando el juez entienda que deba entregarse a la parte victoriosa, como reparación por las dolosas dilaciones «morae reparandae gratia», o cuando se observe imprudencia «impudentia victi» procesal en la parte vencida $^{15}$.

14 La interpretación de esta fuente ha sido causa de una importante controversia doctrinal. Según CHIOVENDA, La condena en costas procesales, trad. DE LA PUENTE Madrid 1928, p. 90 y ss., con esta constitución se confirmaba el principio general y absoluto de la carga de las costas procesales en la parte perdedora de la causa; frente a esta tesis responden numerosos romanistas que indican que este supuesto, de la carga de las costas al vencido, se debe limitar a un número restringido de supuestos: WALDNER, Die Lehre von den Processkosten, Wien 1883, paragrafo 11, o por ERMAN, La restitution des frais en droit romain, Lausanne 1892, p. 124 y ss., siendo PAJARDI, La responsabilitá per le spese e i danni del processo, Milano 1959, p. 263 y ss., quien mejor nos indica la respuesta a la tesis de CHIOVENDA, señalando que no existe en la constitución de Zenón, ni en la legislación justinianea, ningún principio general de responsabilidad objetiva por los gastos del litigio, aun más tomando en consideración otras fuentes como C.I.3,1,13 o, con más énfasis, por Justiniano en I.IV,16,1 (De poena temere litigantum) «... sed pro his introductum est et praefatum iusiurandum, et ut improbus litigator etiam damnum et impensas litis inferre adversario suo cogatur». Sólo los litigantes injustos estarán obligados a indemnizar al adversario de los daños y gastos del litigio.

Para profundizar en el título de la Instituciones justinianea "De poena temere litigantium» es imprescindible consultar BONINI, Contributi di diritto giustinianeo, Bologna 1990, pp. 1-24, quien realiza un detallado análisis de las medidas utilizadas para limitar la excesiva litigiosidad de las partes en los procesos, en particular del «iusiurandum calumniae», de las «actiones in multiplo adversus infitiantes» —en la parágrafo 6 del capt. I- y de la condena a los gastos procesales.

En referencia a los gastos de las partes desde el ámbito estrictamente procesalista consultar: VICENTI, «Ante sententiam appellari potest», opus cit. pp. 104 y ss. así como PROVERA, Lezioni sul processo civile giustinianeo, opus cit. pp. 119 y ss.

15 Para evaluar de forma precisa la cuantía de las costas generadas en un proceso C.I.3,1,13,6 «Sive autem alterutra parte absente, sive utraque praesente lis fuerit decisa, omnes iudices, qui sub imperio nostro constituti sunt, sciant in expensarum causa victum victori esse condemnandum, quamtum pro solitis expensis litium iuraverit, non ignorantes, quod si hoc praetermiserint, ipsi de proprio huismodi poenae subiacebunt et reddere eam parti lesae coartubuntur».

El juez debe declarar en su sentencia, de un modo expreso, que parte será la que deba cargar con las costas generadas en el proceso. Dictada la sentencia, la parte vencedora, a través de un juramento, indicaba el importe de los gastos en costas que había sufrido, y esta declaración era para el juez el techo máximo que se podía exigir a la parte vencida a título de resarcimiento. Si se observa que el juez olvida pronunciarse sobre la cuantía de las costas, estas podrán ser exigidas de su propio patrimonio «... non ignorantes, quod si hoc praetermiserint, ipsi de proprio huismodi poenae subiacebunt et reddere eam parti lesae coartubuntur», un argumento que también se recuerda por Juliano en C.I.3,1,15. 
A este principio general objetivo ${ }^{16}$, pago de costas por la parte condenada, se imponen, en la misma constitución parágrafo 3, tres controvertidas excepciones donde no procede la condena en costas, sino, al contrario, la exención de la condena en costas de la parte vencida por compensación:

- Si reus fidem solvendo praestabit.

- Si actor lite desistet.

- Si iudex eum perspiciet re vera calumniatorem non esse, sed in anticipi causa condemnatum.

Estas excepciones al principio del vencimiento incondicional objetivo dan motivo a una amplia disputa doctrinal: WALDER considera que se admitía la condena absoluta en costas a cargo del actor, subordinándola, respecto a la parte vencida, a la existencia de la culpa, y a cargo del demandado sólo cuando se plantea un litigio manifiestamente injustificable ${ }^{17}$; para ERMAN no se reconoció nunca la condena incondicionada de la parte vencida al pago de las costas, sino que siempre se subordinó a la temeritas, entendida en su sentido de culpa ${ }^{18}$; para tratadistas más actuales como VECCHIONE ${ }^{19}$, más acorde con nuestra opinión antes indicada, la teoría que hace descender la responsabilidad por costas del hecho objetivo del vencimiento en el litigio, no encuentra confirmación en las

$16 \mathrm{Al}$ que podemos encontrar como precedentes algunas fuentes clásicas:

Ulpiano D.5,1,79 «Eum, quem temere adversarium suum in iudicium vocasse constitit, viatica litisque sumtus adversario suo reddere oportebit»

Papiniano D.31,78,2 «Etiam Respublica fideicommissi post moram usuras praestare cogitur, sed damnum, si quod ex ea re fuerit secutum, ad his sarciendum erit, qui post dictam sententiam iudicatum solvere supersederunt. Nec aliud servabitur in litis sumtibus, si ratio litigandi non fuit; ignaviant etenim praetendentes audiri non oportere; quod in tutoribus quoque probatur».

Ulpiano D.50,5,1.1 «Qui excusatione aliqua utuntur, quotiescumque creati fuerint, et si iam ante absoluti sunt, necesse habent appellare: sed si per calumniam et saepius idem adversarius vexandi gratia eius, quem scit perpetua vacatione subnixum, id facere probatus erit, sumtus litis exemplo Decretorum principalium praestare iubeatur ei, quem sine causa saepius inquietabit.»

Con posterioridad, también encontramos este principio en una constitución de Valentiniano C.Th. 4,18,1 «Addimus etiam, ut impensas sumptusque litis, re ad finem deducta, petitoribus praestent».

17 WALDNER, opus cit. parágrafo 11. Para este autor, con la constitución de Zenón, relacionando entre sí el primer y tercer supuesto de exención, se excluye la condena absoluta del demandado vencido en las costas, y se admite sólo la condena del vencido a causa de dolo o culpa lata. Ya que o el desarrollo del proceso puede persuadir al demandado de su error, allanándose a la demanda y quedando libre del pago de las costas, o no se persuade, considerándolo una cuestión dudosa, quedando en ambos supuestos libre del pago. WALDNER sólo considera posible dicha condena a las costas del demandado, cuando dolosamente conociendo su falta de apoyo jurídico, continúa con el litigio, o por que por una inexcusable ignorancia, como culpa grave, no reconoce la injusticia del proceso.

18 ERMAN, opus cit., p. 124 y ss.

19 VECCHIONE, «Spese giudiziali», E.D. pp. 1.122 y 23. 
fuentes si no es en el caso de la temeritas, entre otras causas por dilatación intencionada del proceso, del demandado; más recientemente LALINDE $^{20}$, al igual que ERMAN, considera que la constitución de Zenón estaba orientada a evitar la indolencia judicial de los jueces a imponer las costas, y no cree que se pueda afirmar un criterio objetivo de imposición automática de las mismas, ya que al requerirse un pronunciamiento judicial, dicha condena no se operaba de forma automática. Las costas, en esta interpretación, pueden ser impuestas por el juez, a su libre estimación y en virtud de su auctoritas, al actor o al demandado que han actuado maliciosa o temerariamente y, además, deben ser impuestas siempre al actor o al demandante que ha sido vencido en el litigio, a no ser que lo haya sido por una cuestión razonablemente dudosa que excluya su posible temeridad.

La preocupación del Emperador sobre la carga de las costas en los procesos se hace patente, observando el grave inconveniente que suponía su alta cuantía frente a litigantes con medios económicos limitados, en otros numerosos pasajes de las fuentes, con mayor énfasis en el citado C.I.3,1,13 y en Inst.4,16,1 (de poena temere litigantium) en particular con atención al «improbus litigator»

\section{«...et ut improbus litigator etiam damnum et impensas litis inferre adversario suo cogatur».}

Finalmente, el Emperador introduce, para facilitar la liquidación de las costas, un juramento deferido del juez a la parte vencedora de la causa, para la determinación de la cuantía de los gastos como techo máximo de reembolso de la parte condenada, incluyendo, en el supuesto del «improbus litigator», la posibilidad del resarcimiento de daños, junto con las demás costas procesales, cuando se produjo un retardo doloso en el procedimiento del litigio ${ }^{21}$.

20 LALINDE, Los gastos del proceso en el Derecho histórico español, AHDE 1969, p. 257 y ss.

21 Es sumamente interesante observar como, toda esta regulación de las costas procesales, tuvo una amplia y manifiesta influencia tanto en los glosadores como en nuestro derecho histórico intermedio.

Gracias a la L.78, paragraf. 2, de leg. II, de Papiniano, los glosadores reedificaron la estructura de la teoría de la «iusta causa litigandi», señalando «quia ignorantia excusat a litis sumptibus, etiam olim»; así como, frente a la teoría de la carga de la costas a la parte vencida adjuntaron la regla «si habuerit probabilem causa litigandi, non condemnatur quis expensis». Para comprender el alcance de esta regla de los glosadores, que altera el principio general de imputación de costas, se puede acudir a CHIOVENDA, La condena en costas, opus.cit. pp. 136 y ss., que ofrece dos causas que justificaban la mencionada regla: -Que la condena en las costas en el condenado temerario, dejaba abierto el camino a la no imputación de las mismas al que litiga de forma justificada y fundada-. Así como que la consideración del principio, ya pacíficamente admitido, que cualquier sujeto tiene derecho a plantear un litigio en defensa legitima de un derecho, sin tener que estar coaccionado por la hipotética imputación de los gastos del proceso, que pudieran desalentar su lógicas pretensiones.

Estas mismas precauciones, en la consagración del principio general objetivo de asignar las costas al vencido, se pueden observar en nuestro derecho intermedio. 
Con la vocación de controlar estos gastos procesales, incentivando su tramitación más rápida, se arbitraron también otras medidas referentes a la limitación en

La Partida 3 es, como resulta frecuente en el ámbito procesal, un fiel reflejo de estas influencias romanistas: la ley $8 \mathrm{a}$ del Tit. XXII, de esta Partida nos señala:

«Como el judgador deue condenar en su iuyzio al vencido en las costas que fizo su contendor.

Los que maliciosamente sabiendo que non han derecho en la cosa que mandan mueuen a sus contendores pleytos sobre ella, traiendolos en huyzio, e faziendoles fazer grandes costas, e missiones es gisado que non sean pena, por que los otros se recelen de lo fazer. E por ende dezimos, que los que en esta manera fazen demandas, o se defienden contra otro, non audiendo derecha razón, por lo que deuen fazer, que no tan solamente deue el judgador da por vencido e su pleyto en el yuizio de la demanda a quien lo fiziere, mas aun lo deue condenar en las costas que fizo la otra parte, por razón del pleyto. Empero si el juez entendiere que el vencido se mouiera por alguna derecha razón para demandar o defender su pleyto, non ha por que mandar quel pechen las costas. E esto seria quando alguno que fincasse por heredero de otro demandasse, o defendiesse en juycio por razón de aquellos bienes que heredo, o si alguno otro fiziesse demanda o se amparasse en razón alguna cosa que le fusse dada, o que el ouiesse comparada, o cambiada a buena fe creiendo que aquel que gela diera auia poderia de la enagenar, o si en orto pleyto qualquier y fuesse ya la fecha la jura de la manquadra a que diceu en latin, iuramentum de calumnia, en qualquier destas cosas non deue el juez condenar al vencido en las costas que fizo el vencedor, por que todos deuen asmar que tales pleytos como estos aquellos que los demandan, o que los amparan que lo fazer, e mayormente cuando la jura sobredicha es fecha en el comencamiento del pleyto. Ca entorceron deue sospechar que aquel que jura oluide la saludud de su alma.»

La imposición de costas se regula combinando arbitrariamente tanto el principio de la imputación condicionada de las mismas, como una pena procesal, al considerar en su párrafo primero la situación del litigante con temeritas, junto con el también principio de la iusta causa litigandi, recogido en los párrafos segundo y tercero.

Tres reglas, de inequívoco origen romano, podemos deducir del contenido de la Partida: $1^{\mathbf{a}}$ Que para la condena en costas en primera instancia se exige que sea maliciosa la demanda, o que el litigante, ya sea actor o demandado, carezca de razón derecha o actúe con temeridad. $2^{\mathrm{a}}$ Que corresponde al tribunal sentenciador apreciar y calificar estas circunstancias por los resultados de los autos. $3^{a}$ Que sólo el que es vencido en juicio puede ser condenado en las costas de la primera instancia, no el vencedor, aunque únicamente lo sea en parte de sus pretensiones.

Por lo que refiere a la segunda instancia, la misma Partida 3, en la Ley 27, Tit. 23 (también recogida por la Ley 2a, Tit. 19, Libro XI de la Novísima Recopilación) indica:

«E si fallare que el juicio fue dado derechamente, develo confirmar, e condenar a la parteque se alzo en las costas, que su contendor fizo, segun es constumbre de nuestra corte,..; pero...Cuando el primero juicio se revoca, non debe pechar costas ninguna a las partes».

De esta fuente podemos deducir algunos preceptos propios de la legislación romana: $1^{\circ}$ Siempre que se confirme en todas sus partes la sentencia apelada, debe ser condenado en costas el apelante. $2^{\circ}$ Cuando sea revocatorio el fallo de la segunda instancia, ninguna parte deberá de asumir las costas del contrario. $3^{\circ}$ Cuando en segunda instancia la sentencia sólo realice alguna modificación ventajosa al apelante, no se le debe condenar a las costas, aunque el resto de la sentencia sea confirmatoria. No al contrario, cuando en apelación se indica alguna modificación gravosa al apelante, que si deberá ser condenado al pago de las costas. $4^{\circ}$ Cuando son apelantes ambas partes, cada una deberá de asumir sus costas de segunda instancia.

Consultar LALINDE, Los gastos en el proceso, opus. cit. p. 385 y ss. 
las apelaciones: la inapelabilidad del condenado en contumacia ${ }^{22}$, así como la caducidad de la apelación. En efecto, encontramos una abundante normativa tendiente a limitar la posibilidad de apelar de quien ha sido ya condenado en juicio por contumacia: D.5,1,73,3; D.49,1,23,9; C.I.7,65,123; así como también se indica que si después de un año la causa no ha sido concluida, la apelación se considera caduca, y el juicio original sería considerado como el único valido, a menos que el apelante no probara que el retardo era debido a la gestión del juez $\mathrm{u}$ otras causas de fuerza mayor, caso este en el que se concede una prórroga de un año: Nov.126,2:

...Causa vero appellationis semel intra fatales dies sive ab utraque parte, sive ab uno introducta, nequaquam biennalis temporis decursu in posterum sententia confirmetur, sed verite et iure considerato causae illae, sive una sive utraque parte praesente, legitime decidantur. Et propterea iubemus, ut in eiusmodi casibus non amplius (quemadmodum in hunc usque diem obtinuit) ad primam appellationem omnes cognitores referantur, sed unaquaeque propriam diem praescriptam habeat.

Es la Nov.125, de las quince que JUSTINIANO dedica a la consultatio ante sententiam en su colección de Novelas, la que sugiere una mayor incidencia, bajo la vocación de hacer los litigios más sucintos y económicos «...praesente generali lege hoc perspeximus emendare dilationes negotiis ex hoc fiant, et aliud rursus principium examinationes accipiant», en el nuevo régimen justinianeo de la consultatio.

Esta finalidad se encuentra señalada en la parte inicial del prefacio:

"Quoniam quidam iudicantium post multa litis certamina et plurima a litigantibus facta dispendia in negotiis apud eos motis suggestionibus utuntur ad nostram traquillitatem».

22 Distinta de la absentia per contumacia es la simple ausencia debida a irregularidades en la citación o justificada por motivos como validos, como indica la Nov. 82,5. En este sentido VAN DER WAL, Manuales novellarum iustiniani, Amsterdam 1964, pp. 142 y ss.; así como SCAPINI Principio del doppio grado di giurisdizione e inappellabilita di alcune sentenze nell diritto giustinianeo, en Studi onore C. San Filippo, vol. 5, Milano 1984, pp. 679-706.

23 D.5,1,73,3 Sciendum est, ex peremtorio absentem condemnatum, si appellet, non esse audiendum, si modo per contumaciam defuit; si minus, audietur.

D.49,1,23,3 Eum, qui cognovit Edictum peremtorium secundum ordinis causam dati, placuit non recte provocasse, quum in eius potestate fuerit, ante diem praestitutum pro tribunali respondentem, aut defensum Edicti denuntiationem rumpere.

C.I.7,65,1 Eius, qui per contumaciam absens, quum ad agendam causam vocatus esset, condemnatus est, negotio prius summatim perscrutato, apellatio recipi non potest. 
«Iubemus igitur, nullum iudicantium quolibet modo vel tempore pro causis apud se propositis nunciare ad nostram traquilitatem, sed examinare perfecte causam, et quod eis iustum legitimumque videtur decernere, et si quidem partes cessaverint in iis, quae decreta sunt, exsecutioni contradi sententiam secundum legum virtutem; si autem aliquis putaverit ex prolata novissima sententia se laesum, apellatione utatur legitima, et hoc secundum ordinem legibus definitum examinetur, et perfectum suscipiat terminum. Si autem duo vel amplius fuerint cognitores litis, et aliqua inter eos emergat dissonantia, etiam sic iubemus unum quemquem eorum, secundum quod videtur, ei dare suam sententiam.»

Una norma muy concisa, observando la habitual extensión de las Novelas, donde JUSTINIANO, con un cierto carácter de ruptura frente a la tradicional normativa sobre las consultas al Emperador ${ }^{24}$, ordena a los jueces «... nullum iuducantium quolibet modo vel tempore pro causis apud se propositis nunciare ad nostram tranquillitatem, sed examinare perfecte causam, et quod eis iustum legitimumque videtur decernere».

Ningún juez, frente a las causas promovidas ante él, podrá, como era demasiado frecuente por medio de consejos o directivas, consultar al Emperador, sino que se deberá examinar la causa con detenimiento y pronunciarse sobre lo que considere más justo y legítimo ${ }^{25}$.

Esta Novela, que se inserta como una nota disonante ${ }^{26}$ en relación con el resto de la legislación justinianea, abolió la desmesurada práctica de la «consultatio sententiam», que la legislación de los mismos emperadores había favorecido en el Principado; con el fin tanto de mantener un contacto más directo y eficaz con los distintos tribunales, resolviendo las dudas más polémicas, como para reservarse un cierto monopolio en la interpretatio de la ley.

24 Quizás la falta de una redacción más técnica de la novela, así como la ausencia de previsión del posible riesgo de contradicción con su propia legislación precedente, - donde con frecuencia se reafirma al emperador como última fuente interpretativa de la ley-, hace razonablemente pensar a parte de la doctrina, de la ausencia en estas redacciones de la colaboración de Triboniano, con su estilo más técnico y preciso. Como indica BASSANELLI, L'imperatore, opus cit. pp. 120 y ss., «...mentre all'época dell'emanazione delle Novelle 82 e 113 Triboniano era quaestor sacri palatii e quindi tali Novelle sono a lui attribuibili, la Nov. 125 risale al 534, quando cioe Triboniano era gia uscito di scena». En similares términos BONINI, Studi sull'eta giustininea, opus cit., pp. 86 y ss.

25 Existen otros significativos ejemplos, de limitar la excesiva práctica de la consultatio, como son C.Th. 1,5,4; C.Th.: 11,29,1 y C.I.7,61,3.

26 Como tal es calificada por numerosos romanistas, ver BASANELLI, L'imperatore único creatore e interprete delle leggi e l'autonomia del guidice nel diritto giustinianeo, Milano 1983, pp. 47 y ss. 
Varias son las causas de la desmesurada práctica de la consultatio, en particular la sui generis naturaleza de las cargas públicas durante este período; sus titulares, con frecuencia, no sólo se ocupaban de disputas jurídicas, sino que también cumplían tareas de índole administrativo o militar, y ante tan heterogéneas atribuciones, resultaba lógica la frecuente consulta al Emperador sobre el ejercicio de sus diversas funciones, o simplemente por que una o ambas partes litigiosas, por su relevante peso social o político, hacían arriesgada una decisión con responsabilidad individual.

El procedimiento es conocido: cuando el juez había decidido, frente a dudas fundadas, solicitar una consultatio de la causa, debía también informar a las partes quienes, a su vez, podían incluir sus propias alegaciones recíprocas. Después que el magistrado presentaba su relatio del litigio, el Emperador decidía tomando como base los actos presentados de la causa. Un procedimiento similar era el que se utilizaba cuando, en el supuesto de un tribunal colegiado, los distintos jueces no llegaban a un acuerdo sobre la sentencia más adecuada:

«... Si autem duo vel amplius fuerint cognitores litis, et aliqua inter eos emergat dissonantia, etiam sic iubemus unumquemque eorum, secundum quod videtur, ei dare suam sententiam.»

Otro supuesto que justificaba el recurso a solicitar la decisión al Emperador, era cuando un juez encontraba razonables dudas sobre el contenido o el alcance de una constitución imperial, como son el caso de las Nov. 115 y 151 fruto de una consulta a través de la relatio de un funcionario, supuestos donde se persigue, a causa de cuestiones generalmente promovidas por los magistrados, una interpretatio auténtica de la ley. Sin embargo, estos supuestos no son ciertamente una verdadera consultatio ante sententiam, donde la sentencia era emitida por un tribunal imperial, ya que el juez recibía la respuesta del Emperador en forma de rescriptum, y conforme al mismo daba su propia decisión.

La prohibición impuesta por la Nov. 125, se encuentra profundamente ligada a lo indicado por el propio Emperador en las Nov. 82, 13-14, y Nov. 113 pr.

Nov. 82,13 «Omnis autem iudex, sive cingulum habens, sive aliter iuducans, custodiat leges, et secundum eas proferat sententias, et vel si contingat iussionem nostram in medium, vel si sacram formam, vel si pragmaticam procedere sanctionem, dicentem aliter agi, sequatur legem; nos enim volumus obtinere, quod nostrae vulunt leges. Si enim sub appellatione lis fiat, iudex quidem suscipiat modis omnibus oblatam appellationem, nihil penitus excusans, in quibus omnino licet appellare, 
auxilium vero circa appellationes omnibus adiacet, per quod licet laeso et queri, et mereri correctionem aut ab iis, qui de appellatione iudicant, aut a nobis ipsis, si ad nos sententia referatur».

Nov. 82,14 «Si quid autem audientes iudices putaverint esse dubium damus eis licentiam de his nunciare nobis, et consulere nos, ut discant, quae necessaria sunt, et ita quod agendum est explicent, et faciant iusta simul et rationabilia iudicia.

Nov. 113pr «Omnia secundum nostras leges agi volentes, et harum virtutem servari studentes, perspeximus praesentem scribere legem ad ipsarum legum observationem. Agnovimus enim, quoniam quidam iudicum, volentes, eis qui causas dicunt, tergiversari, et celare suas festinantes dilationes, excusant se frequenter, dicentes, quod sacrae formae, aut sacrae iussiones aut dispositiones spectabilium nostrorum referendariorum insinuatae eis sunt, tanquam disponentes, quemadmodum oporteat negotia examiari aut iudicari».

Nov.113, Capt. I «Et propterea sancimus, ut, dum lis examinatur sive in pecuniariis, vel criminalibus, aut aliis quibuscumque emergentibus causis apud iudices, sive hic, sive in provinciis, neque pragmaticum typum, neque aliam praescriptionem, neque sacram nostram quamlibet ex scripto aut ex non scripto iussionem aut dispositionem in hac regia civitate spectabilium nostrorum referendariorum aut alterius cuiuslibet, disponentem eos quomodo decet inchoatum, examinare aut iudicare negotium, insinuare iudicantibus, aut insinuatam valere, sed secundum generales nostras leges causas examinari et decidi. Quod enim in legum positum est potestate, non egebit aliqua extrinsecus dispositione.»

Estas Novelas son la base de la exigencia que será reclamada por la Nov. 125. La solicitud de un rescriptum no podía ser un medio para paralizar la solución de una controversia, como un expediente dilatorio destinado a retardar la decisión judicial. A tal fin, y como se indica en la Nov. 113, JUSTINIANO señala que los jueces, asumida la cognición de una causa en su jurisdicción, debían examinarla y juzgarla sin tener en cuenta los rescripta o pragmaticae sanctiones procedentes de los privados litependentes y surgidos en la tramitación del litigio. Todo ello con la finalidad de facilitar un procedimiento más veloz y conciso ${ }^{27}$.

Llegados a este punto podemos encontrar una contradicción. Como. sabemos, y brillantemente indica BONINI ${ }^{28}$, la interpretatio de la ley es siempre, a la luz de

27 En atención a un análisis más pormenorizado de la Nov. 113, con particular tratamiento a la prohibición antes indicada, consultar BASSANELLI, L'emperatore, opus cit. p. 83 y ss.; ZILLETI, Studi sul processo civile giustinianeo, Milano, 1965, pp. 43 y 204.

28 BONINI, Introduzione allo studio..., opus cit. p. 74. 
la Nov. $143^{29}$, y como resultado de la nueva orientación sobre legislación en política judicial, monopolio exclusivo del Emperador, según el principio que ve en él la única fuente de la ley; y cada vez que resulte necesaria la aclaración del significado y alcance de una norma, o simplemente para solventar una laguna del ordenamiento, los jueces debían recurrir al Emperador.

Sin embargo en las Nov. 82,13-14, y con más precisión en la 113, se afirma que, asumida la cognición de un litigio, el juez no debe tomar en consideración las consultas particulares al Emperador (rescripta etc.), sino que el juez está obligado a sentenciar sin tomar en consideración tales consultas. Se obtiene, desde esta orientación, una doble finalidad: de un lado se confirma la autonomía del juez en la decisión, y de otro, al mismo tiempo, tal autonomía no llega al punto de consentir al juez la interpretatio final de la ley ${ }^{30}$.

En todo caso, y frente a las posibles contradicciones con el plexo de la legislación novelar, la prohibición establecida por la Nov. 125 es objeto de muy distintas interpretaciones doctrinales, según se dé mayor o menor valor a su contenido literal; si se considera, en consecuencia, que la prohibición indicada por JUSTINIANO tiene un sentido absoluto o, al contrario, relativo; es decir, dejando la posibilidad de acudir a consultas al Emperador en dudas sobre cuestiones de derecho y no sobre los hechos que justifican la causa.

Una posible interpretación es considerar la «consultatio ante sententiam», como nos indica BASSANELLI ${ }^{31}$, como una práctica totalmente asimilada a la apelación, - al poderse considerar una remisión de la causa, con el acuerdo de las partes-, al juez superior, sin que fuera necesario esperar a la sentencia para después presentar su impugnación. En realidad, considerando el auxilio imperial desde esta perspectiva, el recurso a este instituto, no sólo no retrasaba la conclusión del litigio, sino que, en cierta manera, era útil para conseguir una decisión más rápida y acorde a los intereses de las partes.

Si tomamos en cuenta la literalidad del texto, desde esta perspectiva, la prohibición del Emperador parece de carácter absoluto, provocada por la conocida inquietud del uso meramente dilatorio de las «suggestiones» de los jueces; si fuera este el sentido perseguido, nos encontraríamos, como antes indicamos, con

29 Para una interpretación más exhaustiva de esta Novela es imprescindible la consulta de ARCHI, «Sanctissimum templum iustitiae», en Le Pandette di Giustiniano. Storia e fortuna di un codice illustre, Atti Acc. «La Colombaria», n 76, Firenze 1986, p. 222 y ss.

30 BASSANELLI, L'imperatore, opus cit. pp. 83 y ss.; así como VICENTI, Il valore dei precedenti, opus cit. p. 49 y ss.

31 BASSANELLI, L'imperatore, opus cit. p. 110. 
una manifiesta contradicción con lo indicado con frecuencia por JUSTINIANO, $-\mathrm{y}$ particularmente reafirmado en la Nov. 143-, donde se recuerda que el monopolio de la interpretación de la ley reside en el Emperador, quien, de forma contemporánea, ejercita un estricto control de la actividad de los jueces al resolver los litigios.

En realidad, si observamos con detenimiento la Nov. 125, JUSTINIANO no parece que pretenda referirse de forma especifica a amibiguitates sobre la interpretación de las leges, - renunciando a un principio, de monopolio interpretativo imperial, previamente diseñado por él一, sino que la limitación debe orientarse tan sólo a las «relationes» o «suggestiones» sobre cuestiones de hecho de la causa, que los jueces podían solicitar prescindiendo del acuerdo de las partes, retardando de tal modo la cognición de la litigio, más que a la verdadera «consultatio ante sententiam» ${ }^{32}$.

Otra vía, que consideramos más acertada, para interpretar la limitación impuesta por la Nov. 125, es la que se nos ofrece al ser contrastada ésta con el contenido de los Basilicos.

Entorno a la consulta imperial, reproduciendo con bastante fidelidad el principio establecido en las Nov. 82 y 113.1, se encuentran orientados los Bas. 7,1,4-6 y Bas. 2,6,23 respectivamente. Mientras que la prohibición señalada por la Nov.125 viene casi literalmente reproducida en Bas.7,1,18. En todas estas fuentes, se deduce que la verdadera prohibición justinianea estaba destinada a limitar las consultas a los considerandos de hecho, quedando abierta la posibilidad de reclamar aclaraciones sobre los fundamentos de derecho aplicables a la causa.

A la luz de lo indicado por los Basilicos podemos concretar ahora con más precisión el alcance de la limitación imperial: No se admite recurrir a consultas al Emperador, retardando el natural transcurso de la causa, las dudas procedentes de cuestiones de hecho del litigio, sino que sólo se podrán solicitar aclaraciones del significado o alcance del contenido de una lege aplicable al mismo. A este tenor es particularmente interesante Bas. 7,1,17

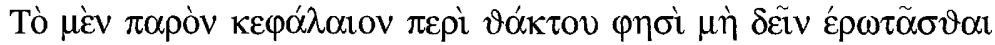

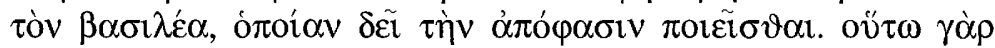

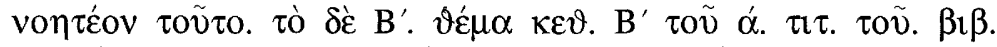

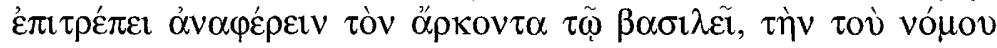

32 En contra de este planteamiento ver SCHERILLO, voz «consultatio», en NNDI IU, 1959; así como LITEWSKI, Consultatio ante sententiam, en ZSS 86, 1969, p. 21 y ss. Ambos autores no hacen ningún tipo de distinción entre el envío completo del litigio, y la simple solicitud de aclaración sobre el contenido o alcance de una lege aplicable al caso y de dudosa interpretación. 


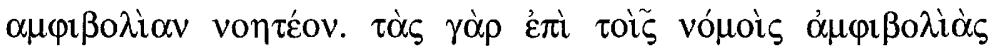

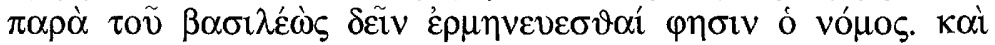

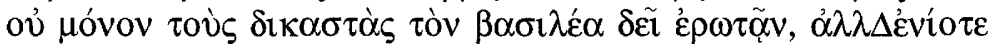

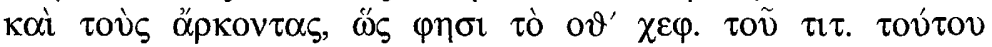

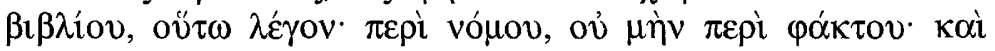

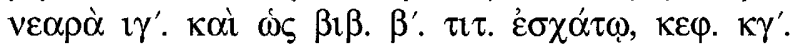

Gran parte de la doctrina moderna ${ }^{33}$, analizando el contenido paralelo de estos scholia de Bas. 7,1,17 y el primer parágrafo de la Nov. 113 , nos señala ${ }^{34}$ la diferencia que el texto con nitidez establece entre la «dubitatio de facto», que no admiten el recurso a la consulta al Emperador, y la «dubitatio de lege», que sí admitía tal auxilio imperial.

Este es el verdadero alcance de la prohibición imperial, las cuestiones de interpretatio judicial admitían su consulta al Emperador, como último y definitivo interprete de la ley; mientras que la resolución de dudas procedentes de los supuestos de hecho planteados en el litigio, son tarea a resolver por el propio juez ante quien se plantea la causa.

En definitiva, este planteamiento nos viene a confirmar como la Novela 125 , en estrecha relación con las cronológicamente posteriores 124 —del 544 - y 126 - del 546-, forma parte del considerado por BONINI ${ }^{35}$ último período legislativo de JUSTINIANO, el que comprende el arco novelar que va del 542 al 548, y que coincide además con la última normativa referida al procedimiento civil, y como tal, son claro intento de solucionar de forma definitiva ciertos problemas, como lentitud y costo de los procesos, surgidos en la praxis de los tribunales, y que gracias a la interpretación ofrecida, no supone una ruptura con el principio general que veía en el Emperador la última fuente interpretativa.

33 ZILLETTI, Studi sul processo civile giustinianeo, Milano 1965, p. 44 y ss., como también PESCANI, Recensione a Bassanelli Sommariva, opus cit., p. 335 y ss.

34 Como acertadamente recuerda VICENTI, Il valore dei precedenti, opus cit. p. 55 y ss.

35 BONINI, Introduzione allo studio dell etá giustinianea, opus cit. p. 67 y ss. 